Article

\title{
Catalytic Conversion of Bio-Oil to Oxygen-Containing Fuels by Acid-Catalyzed Reaction with Olefins and Alcohols over Silica Sulfuric Acid
}

\author{
Zhijun Zhang ${ }^{1,2}$, Shujuan Sui ${ }^{1}$, Fengqiang Wang ${ }^{1}$, Qingwen Wang ${ }^{1, *}$ and Charles U. Pittman, Jr. ${ }^{2, *}$ \\ 1 MOE Key Laboratory of Bio-based Material Science and Technology, Northeast Forestry University, \\ Harbin 150040, China; E-Mails: zzj_1003@163.com (Z.Z.); 15945180240@163.com (S.S.); \\ fqwang@nefu.edu.cn (F.W.) \\ 2 Department of Chemistry, Mississippi State University, Mississippi State, MS 39762, USA \\ * Authors to whom correspondence should be addressed; E-Mails: qwwang@nefu.edu.cn (Q.W.); \\ cpittman@chemistry.msstate.edu (C.U.P.); Tel.: +86-451-8219-1993 (Q.W.); \\ +1-662-325-7616 (C.U.P.); Fax: +86-451-8219-1993 (Q.W.); +1-662-325-7611 (C.U.P.).
}

Received: 28 May 2013; in revised form: 5 August 2013 / Accepted: 14 August 2013 /

Published: 2 September 2013

\begin{abstract}
Crude bio-oil from pine chip fast pyrolysis was upgraded with olefins (1-octene, cyclohexene, 1,7-octadiene, and 2,4,4-trimethylpentene) plus 1-butanol (iso-butanol, $t$-butanol and ethanol) at $120^{\circ} \mathrm{C}$ using a silica sulfuric acid (SSA) catalyst that possesses a good catalytic activity and stability. Gas chromatography-mass spectrometry (GC-MS), Fourier transform infrared spectroscopy (FT-IR) and proton nuclear magnetic resonance ( $\left.{ }^{1} \mathrm{H}-\mathrm{NMR}\right)$ analysis showed that upgrading sharply increased ester content and decreased the amounts of levoglucosan, phenols, polyhydric alcohols and carboxylic acids. Upgrading lowered acidity ( $\mathrm{pH}$ value rose from 2.5 to $>3.5$ ), removed the unpleasant odor and increased hydrocarbon solubility. Water content dramatically decreased from $37.2 \%$ to about $7.0 \%$ and the heating value increased from $12.6 \mathrm{MJ} \cdot \mathrm{kg}^{-1}$ to about $31.9 \mathrm{MJ} \cdot \mathrm{kg}^{-1}$. This work has proved that bio-oil upgrading with a primary olefin plus 1-butanol is a feasible route where all the original heating value of the bio-oil plus the added olefin and alcohol are present in the resulting fuel.
\end{abstract}

Keywords: real bio-oil upgrading; silica sulfuric acid; oxygen-containing fuels; olefin; alcohol 


\section{Introduction}

Conversion of lignocellulosic biomass to fuels and chemicals has attracted increasing attention because of decreasing oil reserves, enhanced worldwide demand for fuels, increased concerns about the increasing release of $\mathrm{CO}_{2}$ by fossil fuel combustion and the inherent conflict between food prices and converting edible carbohydrates into ethanol or plant oils into bio-diesel [1-4]. Bio-oils obtained from fast pyrolysis or biomass liquefaction have the potential to produce valued chemicals and clean, renewable liquid fuels [5]. Bio-oil has a higher energy density than the raw biomass feedstock [5]. However, bio-oil has serious drawbacks including poor volatility, immiscibility with conventional fuels, low heating values per unit weight, catalyst coking, significant water contents, low storage stability, high viscosity, acidic $\mathrm{pH}$ values, a strong unpleasant odor, and corrosiveness [6]. These features severely limit its use as a replacement or supplement for typical diesel or gasoline transportation fuels, making it necessary to reduce water content, raise the heating value, reduce the hydroxyl and carboxylic acid content, reduce hydrophilicity, and convert bio-oil's oxygen molecules into more suitable fuel molecules.

Numerous studies to refine bio-oil have been carried out, including zeolite cracking, hydrodeoxygenation, steam reforming, esterification, and integrated catalytic processing such as hydroprocessing with zeolite catalysis [7-21]. Catalytic cracking/pyrolysis offers significant processing and economic advantages over hydrotreating, but bio-oil cracking produces extensive tars and catalyst coking [3]. Hydrodeoxygenation can increase bio-oil's energy content and stability, however, substantial hydrogen consumption and high pressures are needed [3]. Steam reforming of bio-oils produces syn-gas, which can be converted further into a range of fuels. However, high temperatures are needed and extensive coke deposits formed in the reactor must be gasified [3]. Esterification with alcohols can convert a bio-oil's carboxylic acids to esters, while ketones and aldehydes can form acetals, separately. However, excess alcohol use and removal of water generated in these reactions is required [10].

We recently reported a novel, low temperature upgrading approach where bio-oils were upgraded by adding olefins and reacting these blends over solid acid catalysts [22,23]. In this approach, acid-catalyzed addition reactions of carboxylic acids, phenolic compounds, alcohols and water across olefins all occur simultaneously to form less hydrophilic, higher fuel value products such as esters, alkylated phenols, ethers and alcohols. Water is removed instead of being generated. All these reactions enhance fuel value and remove hydroxyl groups present in bio-oil. By also adding certain co-reagent alcohols in addition to an olefin, serious phase separation of the hydrophilic bio-oil and hydrophobic olefin was reduced. Also, esterification and acetal formation occur and their equilibria are further driven by the removal of the product water from these reactions by addition across olefins [24].

The alcohols selected, like ethanol and butanols can be obtained by biomass fermentation [25], and are fuels themselves. Converting them from a gasoline additive to a bio-oil refining reagents, does not change their ultimate caloric contribution for fuel use. Olefin mixtures can be used, so although olefins are consumed that may have other uses, olefins or olefin mixtures, whatever is cheaper, can be applied. For example, cheaper olefin mixtures can be obtained by pyrolysis of waste polyolefin based plastics. A key point is that the total caloric content of the olefin and alcohol remain within the refined bio-oil fuel along with all of the original caloric content of the raw bio-oil. 
However, undesirable deactivation of solid acid catalysts occurred during the reaction. $\mathrm{Cs}_{2.5} \mathrm{H}_{0.5} \mathrm{PW}_{12} \mathrm{O}_{40}$, an insoluble acidic heteropolyacid salt, exhibits high catalytic activities in the presence of water [26], but it displayed low activity in olefin addition reactions with crude bio-oil [22]. Sulfonic acid resins, Dowex 50W X2 and Amberlyst-15 exhibited higher catalytic activities in bio-oil olefination, but they exhibited low thermal stabilities $\left(<150{ }^{\circ} \mathrm{C}\right)$ and ultimately underwent desulfonation when heated in water [24,27]. Exploration and development of catalysts with good hydrothermal stability and high activity is still needed. Silica sulfuric acid (hereafter designated SSA) is a widely reported water-tolerant strong acid catalyst [28], easily prepared and isolated upon reacting silica gel with neat chlorosulfonic acid. SSA is a superior proton source when compared with many acidic solid supports, such as styrene/divinylbenzene sulfonic acid resins and Nafion-H [28]. SSA was found to be a superior catalyst with good catalytic activity and hydrothermal stability for model bio-oil upgrading with olefins/alcohols in our previous studies [29]. Therefore, in this research, SSA was selected as an improved catalyst for upgrading bio-oil using 1-butanol/1-octene as example reagents. The bio-oil used in this study was derived from fast pyrolysis of pine wood in an auger-fed reactor at $450{ }^{\circ} \mathrm{C}$ as described and characterized earlier [30]. Various olefins (2,4,4-trimethylpentene, cyclohexene and 1,7-octadiene) and alcohols (iso-butanol, $t$-butanol and ethanol) were investigated under similar conditions. The composition of both crude bio-oil and upgraded bio-oil were analyzed using and proton nuclear magnetic resonance $\left({ }^{1} \mathrm{H}-\mathrm{NMR}\right)$, gas chromatography-mass spectrometry (GC-MS), Fourier transform infrared spectroscopy (FT-IR), heating value calorimetry and elemental analysis (for $\mathrm{C}, \mathrm{H}$, and $\mathrm{O}$ ).

\section{Results and Discussion}

\subsection{Bio-Oil Upgrading}

Reactions of crude bio-oil with neat 1-octene, neat 1-butanol and mixed 1-butanol/1-octene, respectively, were carried out for $3 \mathrm{~h}$ at $120{ }^{\circ} \mathrm{C}$ with magnetic stirring. Reactions were carried out in thick-walled closed glass reactors at the pressures generated under these reaction conditions. The $3 \mathrm{~h}$ time period was selected based on extensive previous experimentation at $100-130{ }^{\circ} \mathrm{C}$ on both model compound mixtures [22,23,29,31] and bio-oil [24]. 1-Octene conversions and butanol conversions of these reactions are summarized in Table 1. Crude bio-oil is highly polar, hydrophilic and almost totally immiscible with hydrophobic 1-octene. Therefore, two liquid-phases were formed over the heterogeneous SSA (third phase) after adding 1-octene $(0.25 \mathrm{~g})$ to bio-oil $(1.5 \mathrm{~g})$. This phase separation severely limits mass transfer and lowers the reaction rate. A modest 1-octene conversion of about $24.7 \%$ was attained and serious charring/tar formation on the catalyst had occurred after the reaction. Bio-oil (1.5 g) upgrading with neat 1-butanol $(0.75 \mathrm{~g})$ occurred in one liquid phase over the solid catalyst phase because 1-butanol can dissolve almost all of the components in crude bio-oil, so a good 1-butanol conversion (68.2\%) and no charring or coking occurred.

Compared with the reactions with neat 1-butanol and with neat 1-octene mentioned above, bio-oil $(1.5 \mathrm{~g})$ upgrading with mixed 1-butanol/1-octene $(0.75 \mathrm{~g} / 0.60 \mathrm{~g})$ gave higher 1-butanol $(82.8 \%)$ and 1 -octene $(62.1 \%)$ conversions. These conversions were also higher than those $(80.3 \%$ for 1 -butanol, $50.8 \%$ for 1 -octene) of reactions conducted at the same reaction conditions using Dowex $50 \mathrm{X} 2$ as 
catalyst. SSA showed improved catalytic activity and stability compared to Dowex 50 X2 in real bio-oil upgrading. This is in accord with their performance in model compounds studies [31]. Two major advantages are achieved using mixed 1-octene/1-butanol. First, the 1-butanol reduced the phase separation between bio-oil and 1-octene. This speeds mass transfer and improves olefin conversion. Second, 1-octene consumes water by hydration to 2-octanol and this water loss drives esterification equilibrium reactions between 1-butanol and bio-oil's carboxylic acids towards completion. Furthermore, water removal drives acetal formation from aldehydes and ketones by reacting with 1-butanol. Thus, adding a reagent alcohol further drives the overall upgrading process. 1-butanol eliminated charring and coking which occurred in the upgrading treatments with 1-octene alone. Apparently, the presence of 1-butanol also inhibits bio-oil ageing as is known for methanol [32].

Table 1. Phase state and conversions (\%) of 1-octene and 1-butanol over silica sulfuric acid (SSA) at $120^{\circ} \mathrm{C}$ for $3 \mathrm{~h}^{\mathrm{a}}$.

\begin{tabular}{ccccc}
\hline \multirow{2}{*}{ Reagent mass ratio (g) $^{\mathbf{b}}$} & \multicolumn{2}{c}{ Conversion (\%) } & \multicolumn{2}{c}{ Phase state } \\
\cline { 2 - 5 } & 1-Octene $^{\mathbf{c}}$ & 1-Butanol $^{\mathbf{d}}$ & Before reaction & After reaction $^{\mathrm{e}}$ \\
\hline $1.5 / 0.25 / 0$ & 24.7 & - & Two phases & Two phases, charring \\
$1.5 / 0.6 / 0.75$ & $62.1(50.8)^{\mathrm{f}}$ & $82.8(80.3)^{\mathrm{f}}$ & Emulsion-like & One phase \\
$1.5 / 0 / 0.75$ & - & 68.2 & One phase & One phase \\
\hline
\end{tabular}

Notes: ${ }^{\text {a }}$ Catalyst, $5 \mathrm{wt} \%$ of crude bio-oil; ${ }^{\mathrm{b}}$ Bio-oil/1-octene/1-butanol; ${ }^{\mathrm{c}}$ 1-octene conversion $=1$-Relative area $\%$ of unreacted 1 -octene/relative area $\%$ of 1 -octene before reaction; ${ }^{\mathrm{d}} 1$-butanol conversion $=1$-Relative area $\%$ of unreacted 1-butanol/relative area $\%$ of 1-butanol before reaction; ${ }^{\mathrm{e}} \mathrm{Char} / \mathrm{tar}$ formed on the catalyst;

${ }^{\mathrm{f}}$ The corresponding conversions of 1-octene and 1-butanol obtained at same reaction conditions over Dowex 50 $\mathrm{X} 2$ catalyst (shown in parentheses as bold italic type).

Table 2 shows the conversions of different olefins and alcohols and the phase states of the compositions, both before and after the upgrading reactions. The conversions of three other olefins, trimethylpentene $(64.2 \%)$, cyclohexene $(61.2 \%)$, or 1,7 -octadiene $(59.3 \%)$, were similar to those of 1 -octene $(62.1 \%)$ when used in identical upgrading reactions with 1-butanol.

Table 2. Upgrading bio-oil over SSA with different alcohols and olefins at $120{ }^{\circ} \mathrm{C}$ for $3 \mathrm{~h}^{\mathrm{a}}$.

\begin{tabular}{ccccc}
\hline \multirow{2}{*}{ Alcohols } & \multirow{2}{*}{ Olefins } & \multicolumn{2}{c}{ Conversion $\mathbf{( \% )}$} & Phase state \\
\cline { 3 - 5 } & & Olefins & Alcohols & Before/After \\
\hline$n$-Butanol & 1-octene & 62.1 & 82.8 & Two/One \\
$n$-Butanol & Cyclohexene & 61.2 & 75.5 & Two/One \\
$n$-Butanol & 2,4,4-trimethyl-pentene & 64.2 & 76.2 & Two/One \\
$n$-Butanol & 1,7-octadiene & 59.3 & 80.2 & Two/One \\
Isobutanol & 1-octene & 61.5 & 81.9 & Two/One \\
$t$-Butanol & 1-octene & 60.8 & 84.2 & Two/Two \\
Ethanol & 1-octene & 34.4 & 80.7 & Two/Two \\
\hline
\end{tabular}

Note: ${ }^{\text {a }}$ Weight ratio, raw bio-oil:alcohol:olefin $=1.5: 0.6: 0.75 ; \mathrm{SSA}, 5 \mathrm{wt} \%$ of raw bio-oil.

The 1-butanol conversions were also similar. Significantly, two-phase starting mixtures become a single phase by the end of the reaction. This indicates clearly that the initially charged raw bio-oil had become significantly less hydrophilic as reactions with olefin and 1-butanol proceeded. It also 
confirms that other olefins, such as olefin refinery cuts, olefin mixtures obtained by pyrolysis of waste polyolefin based plastics could be successfully employed for upgrading.

Ethanol, iso-butanol, and $t$-butanol, all of which can be obtained by biomass fermentation were also selected as co-reagents (Table 2). Like 1-butanol, addition of all these alcohols inhibited coking of the catalysts to various extents. When $t$-butanol and iso-butanol was used, 1-octene conversions remained high (ca. 60\%), close to the value that was found with using 1-butanol (62.1\%). However, when the same amount (weight) of ethanol was used, 1-octene conversion decreased to less than $35 \%$. After the reaction, phase separation still existed. This is because ethanol is too polar to reduce phase separation as well as 1-butanol.

\subsection{Comparison of Organic Components of Crude and Upgraded Bio-Oils}

GC-MS was used to separate and identify molecular components allowing a comparison of the crude and upgraded bio-oils. Figure 1 provides three, highly compressed total ion chromatograms of crude bio-oil, bio-oil upgraded with 1-octene/1-butanol, and bio-oil upgraded with neat 1-octene.

Figure 1. Gas chromatography-mass spectrometry (GC-MS) spectroscopy of (A) crude bio-oil; (B) bio-oil upgraded with neat 1-octene (weight ratio, raw bio-oil:1-octene = 1.5:0.6); and $(\mathbf{C})$ bio-oil upgraded with 1-octene/1-butanol (weight ratio, raw bio-oil:1-octene $1=1.5: 0.6: 0.75)$ at $120{ }^{\circ} \mathrm{C}$ for $3 \mathrm{~h}$ over silica sulfuric acid (SSA).

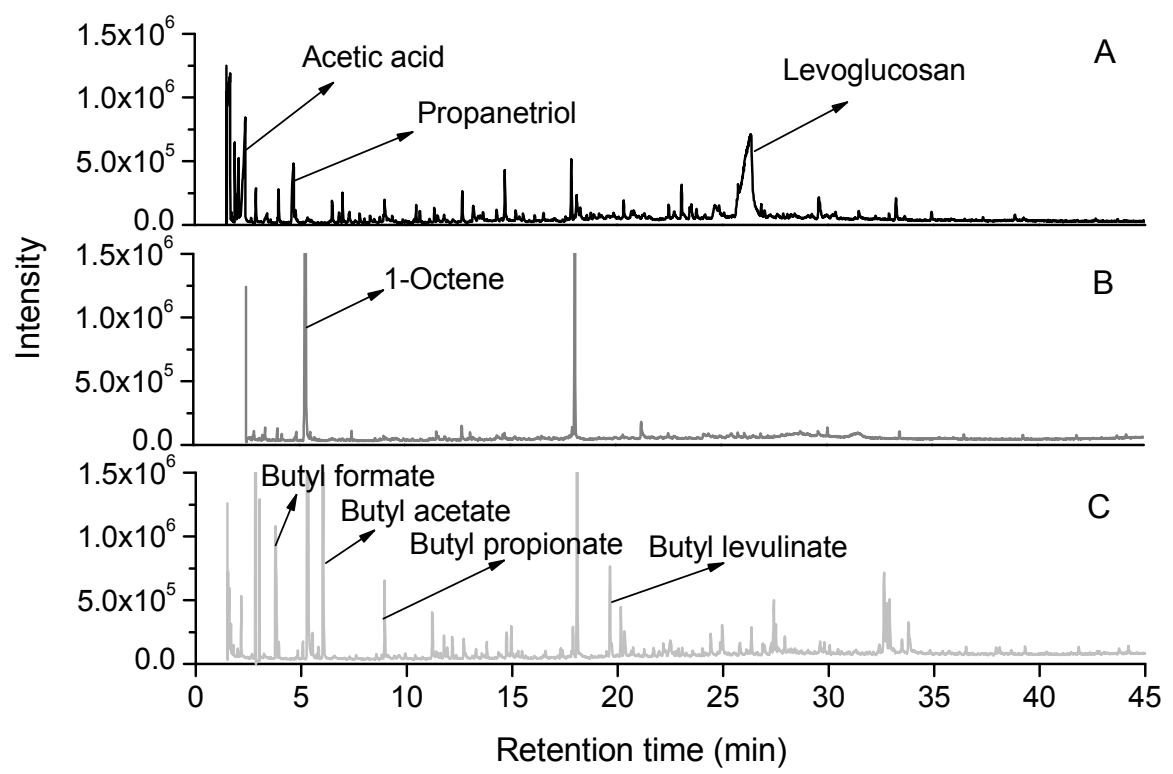

While some features are common, the three GC-MS traces show that widely different compositions exist in these three samples. Clearly, the crude bio-oil composition is largely changed and the upgrading with mixed 1-butanol/1-octene produces a much different composition than the product reacted with 1-octene alone. Bio-oil has a complex array of highly oxygenated components, which are nearly all oxygenated organic species. These include anhydro-sugars, carboxylic acids, phenols, aldehydes, ketones, mono- and polyalcohols, ethers, esters, furans, hydroxyaldehydes, hydroxyketones, etc. [5,12,30]. Based on the total ion current obtained, the quantitated portions of these various organic components in both the crude bio-oil and bio-oil upgraded with 1-octene/1-butanol were identified and their 
amounts in these liquids (peak area percentages which are proportional to the molar compositions) are listed in Table 3 (also see Table A1 for the crude bio-oil and Table A2 for bio-oil upgraded with 1-octene/1-butanol).

Table 3. A general breakdown of the components of raw bio-oil ${ }^{\mathrm{a}}$ and bio-oil upgraded with 1 -octene/1-butanol at $120^{\circ} \mathrm{C}$ for $3 \mathrm{~h}^{\mathrm{b}}$.

\begin{tabular}{|c|c|c|}
\hline Components & Raw bio-oil (Area \%) & Upgraded bio-oil (Area \%) \\
\hline Carboxylic acids & 12.67 & 1.00 \\
\hline Phenols & 10.64 & 4.42 \\
\hline Furans & 1.64 & 0.13 \\
\hline Ketones and aldehydes ${ }^{b}$ & 4.66 & 0.78 \\
\hline Alcohols & 11.97 & $13.55^{\mathrm{c}}$ \\
\hline Esters and acetals & 2.17 & 25.82 \\
\hline Others & 4.67 & 46.80 \\
\hline Sugars & 51.98 & 4.88 \\
\hline Acetals and ethers & nd $^{\mathrm{d}}$ & 2.62 \\
\hline
\end{tabular}

Notes: ${ }^{a}$ The bio-oil was produced by fast pyrolysis in an auger-fed reactor at $450{ }^{\circ} \mathrm{C}$ from southern pine sawdust using the methanol described in reference $30 ;{ }^{b}$ The bio-oil/1-octene/1-butanol weight ratio (g) used was $1.5 / 0.6 / 0.75 ;{ }^{\mathrm{c}}$ A portion of this must be due to added, but still unreacted 1-butanol; ${ }^{\mathrm{d}}$ nd: no detected.

After upgrading, the levoglucosan (1,6-anhydro- $\beta$-D-glucopyranose) peak which also includes other anhydrosugars, was dramatically decreased from $45 \%$ to less than $0.2 \%$. This peak represented the most abundant organic component in the starting crude bio-oil. Compared to two specific esters identified in crude bio-oil, more than 20 esters were detected in bio-oil upgraded with mixed 1-butanol/1-octene. These accounted for about $25 \%$ of the total corresponding peak area. These included esters formed by carboxylic acid additions across 1-octene and octene isomers, $n$-butyl esters formed from 1-butanol and carboxylic acids and various octyl esters formed from octanols. These octanols were formed by water uptake by octene isomers. Although no levulinic acid was detected in crude bio-oil, levulinic acid butyl ester was the third most abundant ester after butyl formate and butyl acetate, accounting for about $2 \%$ peak area after upgrading. Levulinic acid was formed by acid-catalyzed dehydration of monosaccharides during upgrading. This is known to occur in aqueous solutions (Scheme 1) [3,33].

Scheme 1. Steps involved in the conversion of hexoses to levulinic acid.

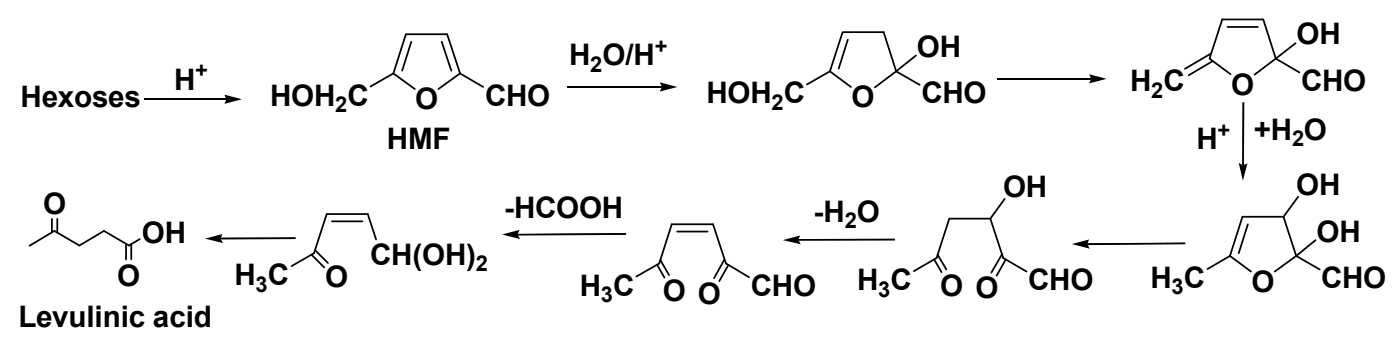

The total content (in area \%) of phenol compounds dropped from about $10.6 \%$ in crude bio-oil to $2.7 \%$ in upgraded bio-oil. Various octyl-substituted phenols were observed from both $O$-alkylation and $C$-alkylation reactions with octene isomers. Both the number and content of furans, ketones and aldehydes decreased after upgrading, while some acetals were detected. 
It was noteworthy that the polyhydric alcohols content decreased dramatically from a combined area percent of $12 \%$ to less than $0.1 \%$ after upgrading. This lowers the viscosity and hydrophilicity of the product. Three 1-octene isomers were observed after the reactions along with some amount of their hydrates, 2-octanol, 3-octanol and 4-octanol, but no oligomeric or fragmented olefins from octenes were detected.

It is apparent that the amounts of esters sharply increased, while the amounts of water, carboxylic acids, anhydromonosaccharides, phenols, furan derivatives, polyhydric alcohols and aldehydes decreased. These changes increase both stability and hydrocarbon blending ability of the upgraded bio-oil. These results showed that 1-octene/1-butanol upgrading is feasible and it produces less hydrophilic fuel molecules.

\subsection{FT-IR Analysis of Crude Bio-Oil and Upgraded Bio-Oil}

The FT-IR spectra of crude and 1-octene/1-butanol upgraded oils are given in Figure 2. Obvious changes occurred. The broad intense hydrogen bonded $\mathrm{O}-\mathrm{H}$ stretching absorption between 3200 and $3600 \mathrm{~cm}^{-1}$ decreased substantially upon upgrading due to decreases of water, carboxylic acids, polyols and phenols present in crude bio-oil. This occurs despite the addition of large amounts of 1-butanol reagent at the start of the upgrading reaction, emphasizing the extensive reactions that this alcohol undergoes during the process. However, 1-octene and 1-butanol add mass to the product which also "dilutes" the existing - $\mathrm{OH}$ absorption intensity. A strong carbonyl stretching band between 1650 and $1780 \mathrm{~cm}^{-1}$ in both the crude and upgraded bio-oil was present, while $\mathrm{C}-\mathrm{O}$ stretching vibrations between 900 and $1300 \mathrm{~cm}^{-1}(1240,1070,1044,1022,950)$ were strengthened in the upgraded bio-oil indicating the formation of esters and ethers [34]. The $\mathrm{C}-\mathrm{H}$ stretching vibration between 2850 and $2950 \mathrm{~cm}^{-1}$ and the $\mathrm{C}-\mathrm{H}$ deformation vibrations between 1375 and $1475 \mathrm{~cm}^{-1}$ belong to $\left(\mathrm{sp}^{3}\right)$ aliphatic portions of molecules in these liquids [35]. The relative intensity in these two regions sharply increased in the upgraded bio-oil due to the formation of butyl and octyl esters, ethers and acetals. Absorbances appearing at 3083 and $1640 \mathrm{~cm}^{-1}$, respectively, represent $\mathrm{sp}^{2}$-hybridized $\mathrm{C}-\mathrm{H}$ and $\mathrm{C}=\mathrm{C}$ stretching vibrations in $\mathrm{RC}=\mathrm{CH}_{2}$ and $\mathrm{RCH}=\mathrm{CHR}$ groups, while the out-of-plane $\mathrm{C}-\mathrm{H}$ deformations appear at 990 and $910 \mathrm{~cm}^{-1}$. These less intense absorptions are due mostly to octene isomers in the upgraded sample.

Figure 2. Fourier transform infrared spectroscopy (FT-IR) spectra of crude bio-oil and bio-oil upgraded with a bio-oil/1-octene/1-butanol wt ratio of 1.5/0.6/0.75 at $120{ }^{\circ} \mathrm{C}$ after $3 \mathrm{~h}$ over SSA.

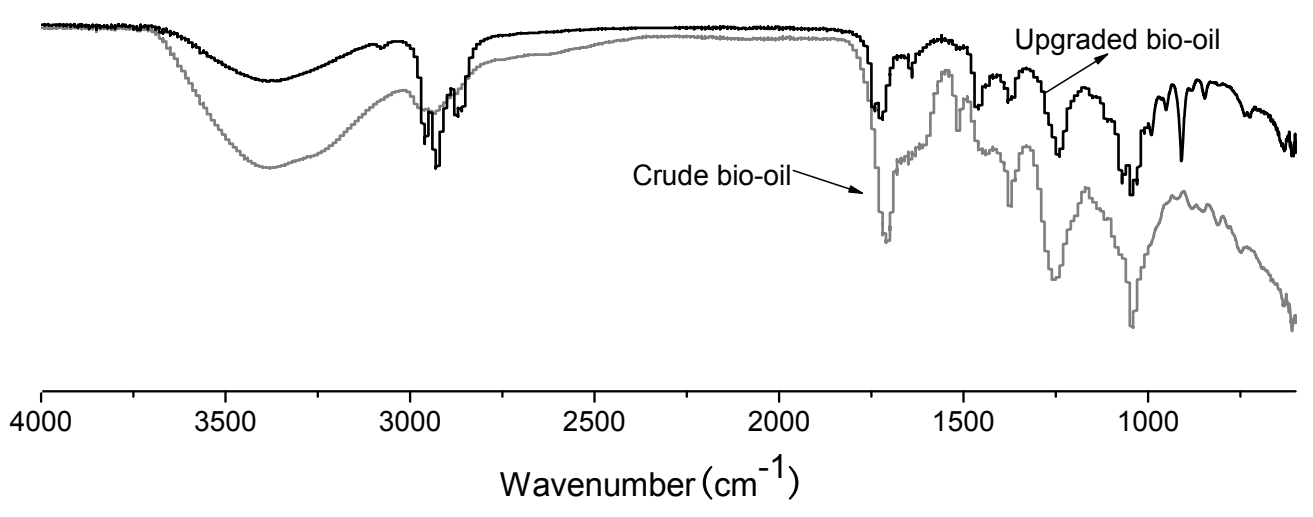




\subsection{Comparing the ${ }^{1} H$ NMR Spectra of Crude and Upgraded Bio-Oils}

Figure 3 shows the ${ }^{1} \mathrm{H}-\mathrm{NMR}$ spectra of crude bio-oil and bio-oil upgraded with 1-butanol/1-octene at $120{ }^{\circ} \mathrm{C}$ after $3 \mathrm{~h}$ over SSA. Table 4 provides a summary of types of proton environments in specific functional groups observed and their integrated areas in specific chemical shift ranges. The details and background supporting these assignments have been discussed extensively in previous reports [30,36]. Most strong resonances appear within the 4.2-6.2 ppm range for crude bio-oil. This is where protons in $-\mathrm{CH}_{\mathrm{n}}-\mathrm{O}-$ and $\mathrm{HC}=\mathrm{C}$ (conjugated) functionalities appear. A second region with strong proton resonances occurs from 0 to $2.2 \mathrm{ppm}$. These are aliphatic $\mathrm{CH}_{3}, \mathrm{CH}_{2}$ and aliphatic $\mathrm{OH}$ protons. The integrated intensity of this region (e.g., 0.0 to 1.6) goes up dramatically after upgrading (see Table 4) due to octene and butanol reactions that put butyl and octyl functions into the upgraded oil. The sharp decrease in integrated intensity in the 4.2 to $6.4 \mathrm{ppm}$ region agrees with the loss of the 1,6 -anhydro- $\beta$-D-glucopyranose and glycerin in the GC-MS total ion chromatogram. Drastic decreases in anhydrosugars and some polyols occur on upgrading bio-oil and this is consistent with both ${ }^{1} \mathrm{H}-\mathrm{NMR}$ and GC-MS analysis (Table 3).

Figure 3. ${ }^{1} \mathrm{H}-\mathrm{NMR}$ spectra of (a) crude bio-oil and (b) bio-oil upgraded with a bio-oil/ 1-octene/1-butanol wt ratio of $1.5 / 0.6 / 0.75$ at $120^{\circ} \mathrm{C}$ after $3 \mathrm{~h}$ over SSA.

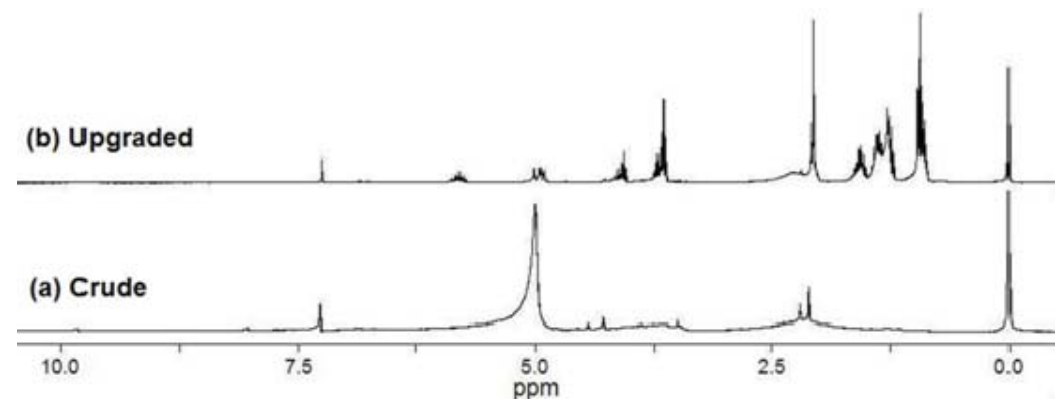

Phenolic aromatic protons appear in the $6.8-8.0 \mathrm{ppm}$ range, where integration gives a hydrogen content of $3.76 \%$ for crude bio-oil. This is consistent with the identification of phenolic compounds in GC-MS analysis (Table 3). Upgrading reduces theses protons to below $1 \%$ of the total protons observed. Carboxylic acid $(-\mathrm{COOH})$ or aldehyde $(-\mathrm{CHO})$ protons appear around $8-10 \mathrm{ppm}$ and occupy ca. $0.85 \%$ of peak area in crude bio-oil. As expected, the contributions of these protons drop in the upgraded sample due to esterification of carboxyl groups by 1-butanol, carboxyl additions across octene and conversion of some aldehydes to acetals.

The increase in integrated intensity in the region from 4.2 to $3.0 \mathrm{ppm}$ upon upgrading agrees with the conversion of carboxylic acids to butyl and octyl esters and with acetal formation. These compounds all have protons on carbon which is bonded to $\mathrm{sp}^{3}$-hybridized oxygen. These results are also in accord with the GC-MS results (Table 3). The appearance of peaks between 6.4-6.8 ppm in the upgraded bio-oil, are assigned to non-conjugated $\mathrm{HC}=\mathrm{C}$ protons present in unreacted octene isomers. 
Table 4. Nuclear magnetic resonance $\left({ }^{1} \mathrm{H}-\mathrm{NMR}\right)$ chemical shift assignments and relative abundances for crude bio-oil and upgraded bio-oil ${ }^{\mathrm{a}}$.

\begin{tabular}{cccc}
\hline \multirow{2}{*}{ Chemical shift (ppm) } & Type of protons & \multicolumn{2}{c}{ Hydrogen content (\% area of total) } \\
\cline { 2 - 4 } & Crude bio-oil & Upgraded bio-oil $^{\mathbf{b}}$ \\
\hline $10.0-8.0$ & $-\mathrm{CHO},-\mathrm{COOH}$, downfield $\mathrm{ArH}$ & 0.85 & 0.04 \\
$8.0-6.8$ & $\mathrm{ArH}, \mathrm{ArOH}, \mathrm{HC}=\mathrm{C}$ (conjugated) & 3.76 & 0.79 \\
$6.8-6.4$ & $\underline{\mathrm{HC}}=\mathrm{C}($ nonconjugated) & 0.00 & 0.82 \\
$6.4-4.2$ & $-\mathrm{CH}_{\mathrm{n}}-\mathrm{O}-, \mathrm{HC}=\mathrm{C}$ (nonconjugated) & 64.54 & 6.47 \\
$4.2-3.0$ & $\mathrm{CH}_{3}-\mathrm{O}-,-\mathrm{CH}_{2}-\mathrm{O}-,-\mathrm{CH}-\mathrm{O}-$ & 9.23 & 13.6 \\
$3.0-2.2$ & $\mathrm{CH}_{3} \mathrm{C}(=\mathrm{O})-, \mathrm{CH}_{3}-\mathrm{Ar},-\mathrm{CH}_{2} \mathrm{Ar}-$ & 1.06 & 0.36 \\
$2.2-1.6$ & $-\mathrm{CH}_{2}-$, aliphatic $\mathrm{OH}$ & 20.46 & 19.92 \\
$1.6-0.0$ & $-\mathrm{CH}_{3},-\mathrm{CH}_{2}-$ & 0.10 & 58.00 \\
\hline
\end{tabular}

Notes: ${ }^{\mathrm{a}}$ The chemical shift regions overlap somewhat and $\mathrm{OH}$ protons from water, alcohols, and carboxylic acids are $\mathrm{pH}$-dependent and can be found over a wide range; ${ }^{\mathrm{b}}$ Upgrading conditions: weight ratio, crude bio-oil: 1-octene:1-butanol $=1.5: 0.6: 0.75 ; \mathrm{SSA}, 5$ wt. $\%$ of crude bio-oil; $120^{\circ} \mathrm{C} ; 3 \mathrm{~h}$.

\subsection{Properties of Upgraded Bio-Oil}

Some representative properties of the crude bio-oil versus bio-oil upgraded with a bio-oil/1-butanol/1-octene ratio of 1.5/0.75/0.6 at $120{ }^{\circ} \mathrm{C}$ after $3 \mathrm{~h}$ over SSA are summarized in Table 5. The bio-oil's appearance was not obviously changed before and after upgrading, but its odor changed noticeably from a very unpleasant heavy smoke-like aroma to a banana-like fragrance. This change results mainly from the $O$-alkylation and $C$-alkylation of phenolic compounds (phenol, guaiacol, methyl phenols, etc.), a decrease of levoglucosan, and formation of large amounts of butyl acetate and other esters during upgrading.

Table 5. Fuel properties of crude bio-oil and bio-oil upgraded with 1-octene/1-butanol over SSA for $3 \mathrm{~h}^{\text {a }}$.

\begin{tabular}{|c|c|c|}
\hline Properties & Crude Bio-oil & Upgraded Bio-oil \\
\hline Appearance & Dark brown liquid & Brown liquid \\
\hline Odor & Heavy smoke-like & Banana-like \\
\hline Water content (wt \%) & 37.19 & 7.06 \\
\hline $\operatorname{HHV}\left(\mathrm{MJ} \cdot \mathrm{kg}^{-1}\right)$ & 12.55 & 31.91 \\
\hline $\mathrm{pH}$ value & 2.62 & 3.53 \\
\hline Density $\left(\mathrm{g} \cdot \mathrm{cm}^{-3}\right)$ & 1.19 & 0.89 \\
\hline Viscosity $\left(\mathrm{mm}^{2} \cdot \mathrm{s}^{-1}\right) @ 40{ }^{\circ} \mathrm{C}$ & 15.45 & $5.5(6.13)^{\mathrm{c}}$ \\
\hline $\mathrm{C}(\mathrm{wt} \%)$ & 59.71 & 65.78 \\
\hline $\mathrm{H}(\mathrm{wt} \%)$ & 8.09 & 11.48 \\
\hline $\mathrm{O}(\mathrm{wt} \%)$ & 32.08 & 22.56 \\
\hline $\mathrm{N}(\mathrm{wt} \%)$ & 0.11 & 0.17 \\
\hline Addition of water & Emulsion liquid & Phase separated \\
\hline${ }^{\mathrm{b}}$ Mix with hexane-toluene & Two or more phases & One phase \\
\hline
\end{tabular}


The elemental composition (wt \%) changed from $59.71 \% \mathrm{C}, 8.09 \% \mathrm{H}, 32.08 \% \mathrm{O}$ and $0.11 \% \mathrm{~N}$ for crude bio-oil to $65.78 \% \mathrm{C}, 11.48 \% \mathrm{H}, 22.56 \% \mathrm{O}$ and $0.17 \% \mathrm{~N}$ for the upgraded bio-oil. The increase of $\mathrm{C}$ and $\mathrm{H}$-content with the decrease of O-content enhances the calorific value of upgraded bio-oil. The heating value of upgraded bio-oil was $31.9 \mathrm{MJ} \cdot \mathrm{kg}^{-1}$, well over double that of the crude bio-oil $\left(12.55 \mathrm{MJ} \cdot \mathrm{kg}^{-1}\right)$. This increase is the result of the presence of residual 1-butanol [higher heating value (HHV): $36.1 \mathrm{MJ} \cdot \mathrm{kg}^{-1}$ ] and 1-octene (HHV: $47.3 \mathrm{MJ} \cdot \mathrm{kg}^{-1}$ ) and their many reaction products with crude bio-oil components. The water content of the upgraded bio-oil was reduced from $37.2 \%$ to $\approx 7.0 \%$. This decrease is due to the acid-catalyzed addition of water across the octene as well as the overall mass increase of the product from 1-butanol/1-octene addition. This removes portions of the original high bio-oil water content as well as some of the water formed via esterification, ether and acetal formation. The $\mathrm{pH}$ value of upgraded bio-oil rose from 2.62 to 3.53 .

Crude bio-oil has a complex multi-microphase structure [37]. After small amounts of water are added to crude bio-oil, the appearance stays the same. However, as more water is added to this crude bio-oil, clear phase separations occur where both water and organics are present in both phases (see Figure 4a). In contrast, upon the addition of water into the upgraded bio-oil, two sharp phases were formed with very little incorporation of this added water to the upgraded bio-oil (see Figure 4b). This illustrated that the upgraded bio-oil, with all of its original oxygen still present, is far less hydrophilic than the original crude bio-oil. The upgraded bio-oil's density was lowered below $1.0 \mathrm{~g} \cdot \mathrm{cm}^{-3}$ and it floated on top of added water (Figure $\left.4 \mathrm{~b}\right)$. The upgraded bio-oil $(0.5 \mathrm{~g})$ was miscible with hexane/toluene $(0.25 \mathrm{~g} / 0.75 \mathrm{~g})$ (Figure $4 \mathrm{c})$. This suggests these upgraded liquids can be blended with biodiesel or other petroleum-based products. Clearly, the upgraded products had become more hydrophobic.

Figure 4. Miscibility of (a) crude bio-oil with water; (b) Upgraded bio-oil with water; (c) Upgraded bio-oil with hexane/toluene (Bio-oil was upgraded with a bio-oil/1-octene/ 1-butanol wt ratio of $1.5 / 0.6 / 0.75$ at $120^{\circ} \mathrm{C}$ after $3 \mathrm{~h}$ over SSA).

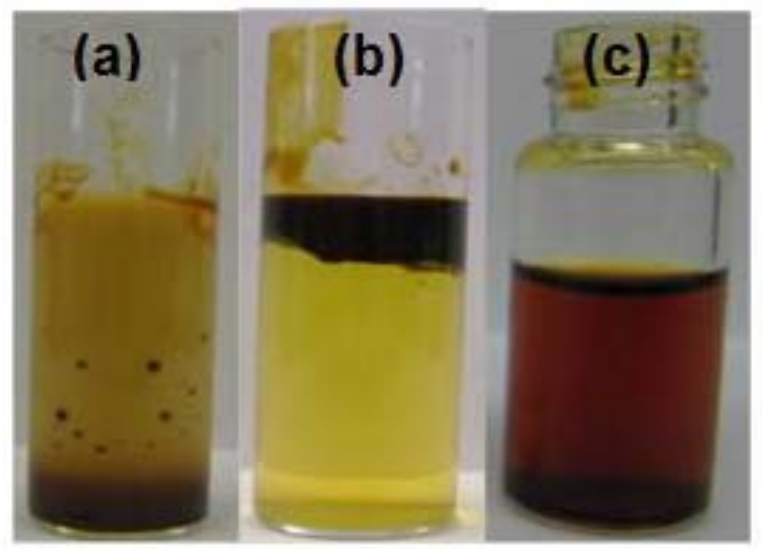

Initial raw bio-oil viscosity was $15.45 \mathrm{~mm}^{2} \cdot \mathrm{s}^{-1}$ compared to $5.5 \mathrm{~mm}^{2} \cdot \mathrm{s}^{-1}$ for the upgraded bio-oil. Subsequent raw bio-oil kinetic viscosity could not be tested as it polymerized to a very thick condition. The viscosity changes over $24 \mathrm{~h}$ for the upgraded product were slight, with highest viscosity of $6.13 \mathrm{~mm}^{2} \cdot \mathrm{s}^{-1}$ demonstrated at $18 \mathrm{~h}$ of $90{ }^{\circ} \mathrm{C}$ heating. This was only a $11.5 \%$ increase in viscosity. 
Clearly, the current example treatments produced a highly stable bio-oil that could be shipped and stored at ambient temperatures without substantial aging over time.

\subsection{Proposed Reaction Pathways}

It is not feasible to figure out all the reactions involved in this upgrading process because of the bio-oil's complexity. However, some pathways involved in reactions of bio-oil components and olefins/alcohols were postulated based on the product analyses and the discussion already provided. This overall picture is given in Figure 5. Other evidence comes from our previous study of model compounds and their mixtures to simulate simple bio-oils under these upgrading conditions [22-24,29,31]. Protonation of olefins and subsequent proton loss and reprotonation steps generated the isomerized olefins and their cation intermediates. Simultaneously, a series of competing reactions occur, where bio-oil's components: water, carboxylic acids, phenols and alcohols add to these alkyl cations. Protonation of alcohols and carboxylic acids also occurs reversibly. Overall, this leads to hydration, esterification, $O$-alkylation and etherification forming alcohols, esters, phenol $O$-alkylates and ethers, respectively. Additional competing reactions among carboxylic acids, aldehydes, alcohols, $O$-alkylated phenols and levulinic acid with alcohol occurred, respectively, generating esters, acetals, ethers, $C$-alkylated and bis- $C$-alkylated phenols and alkyl levulinates. $O$-Alkylated phenols can isomerize via a Friedel Crafts mechanism to the thermodynamically more stable $C$-alkylated phenols. Dehydration of D-glucose gives 5-hydroxymethylfurfural (HMF). The subsequent hydration of HMF to its hemiacetal in acidic media took placed followed by hydration, ring-opening, loss of water and formic acid to form levulinic acid (Scheme 2). This, in turn, is converted to alkyl levulinates by alcohols. Intermolecular etherification of alcohols further formed ethers.

Scheme 2. Synthetic route to SSA.

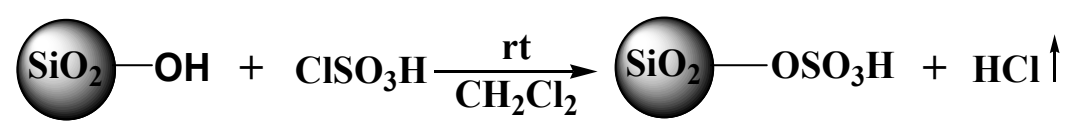

The esterification, acetal formation and etherification reactions all generated water. The first two classes of reactions are in equilibrium under the upgrading reaction conditions. These equilibria have equilibrium constants that limit conversion when significant amounts of water are present. Further water is generated by monosaccharide and anhydrosugar dehydration sequences. When these reactions are considered along with the large amount of water in raw bio-oil, the key reason for the success of this upgrading process is the role of olefin acid-catalyzed hydration. Olefin hydration removes water. As water concentration drops, esterification and acetal formation equilibria shift towards ester and acetal products. A complex interaction of many different reaction rates and positions of a large number of equilibria control the product distributions evolution with time. 
Figure 5. Reactions of bio-oil components with example olefin (1-octene) and alcohol (1-butanol).

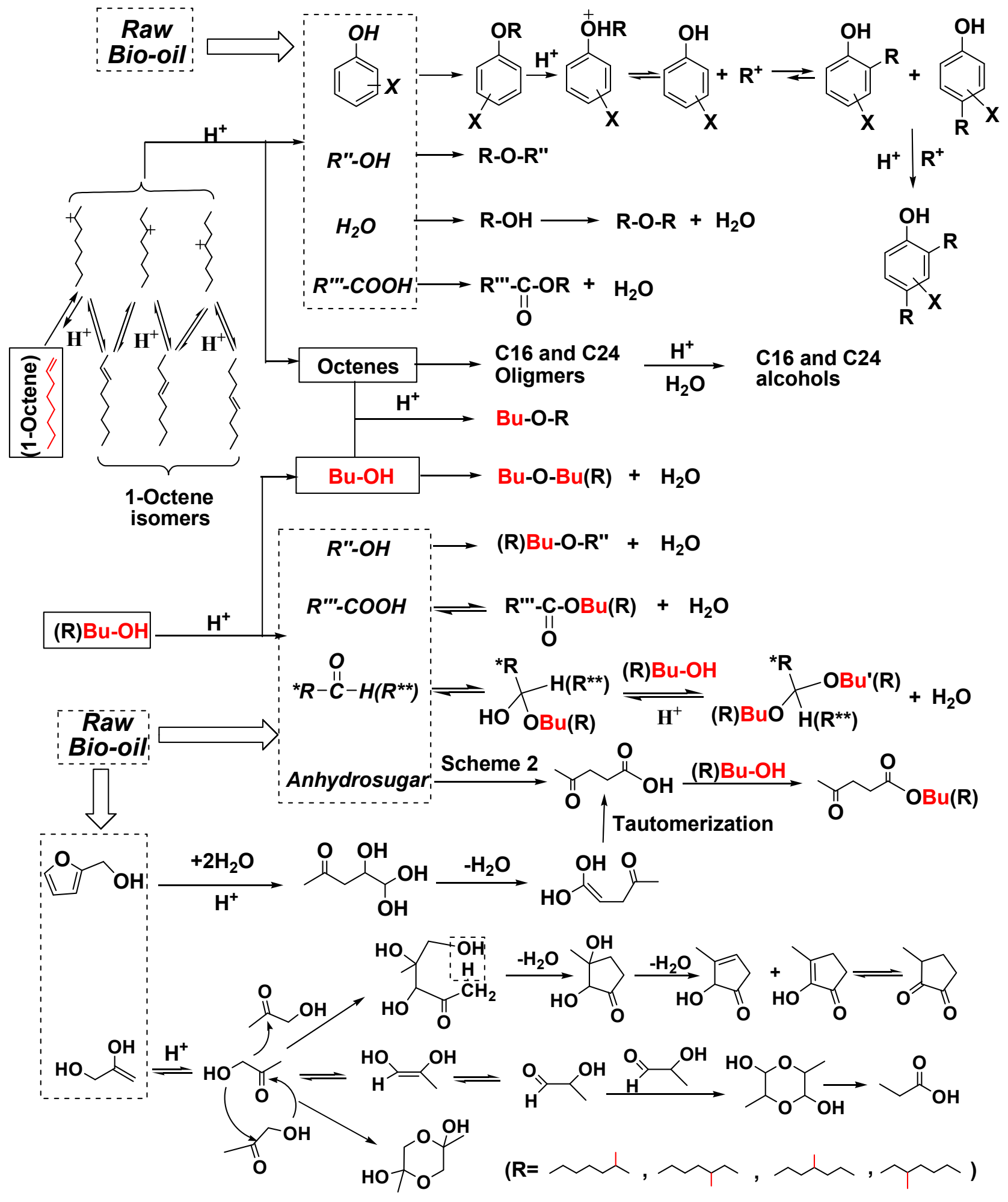

\subsection{Closing Statement}

Upgrading bio-oil by reaction with olefins and an alcohol offers an atom-economic route for partially refining bio-oil to combustible and stable oxygen-containing organic fuels while removing water. Thus, all the atoms in the bio-oil and reagent alcohol and olefins remain in the product without any loss of heating value due to the loss of product molecules containing $\mathrm{C}$ or $\mathrm{H}$. Esterification, 
etherification, olefin hydration, phenol alkylation (both $O$ - and $C$-), acetal formation, sugar dehydration etc. are all taking place during the upgrading process. Olefin addition helps drive the carboxylic acid esterification with alcohol equilibrium by removing water via double bond hydration, followed by some etherification of their hydrates (alcohols) formed. Carboxylic acid addition across olefins also generates esters. Alcohols also react with aldehydes and ketones to form acetals and water in equilibrium. Again, olefin hydration can assistant these equilibria move toward acetals. Upgrading treatment sharply increased ester content and decreased the amounts of levoglucosan, polyhydric alcohols and organic acids. This leads to the improvement of bio-oil's fuel qualities as seen from its density decrease from 1.19 to $0.89 \mathrm{~g} \cdot \mathrm{cm}^{-3}, \mathrm{pH}$ value increase from 2.5 to $>3.5$, calorific value increase from $12.6 \mathrm{MJ} \cdot \mathrm{kg}^{-1}$ to about $31.9 \mathrm{MJ} \cdot \mathrm{kg}^{-1}$, and water content decrease from $32.7 \%$ to about $7.0 \%$. However, this upgrading process is far from being optimized. A large process development effort is needed to adjust the amounts of olefins and alcohol, and optimize the temperature that will give a satisfactory upgraded product for different bio-oil feeds containing different amounts of water.

Cost optimizations have not been studied because no continuous flow reactions have been undertaken over fixed catalyst beds as a function of temperature. Such studies are critical for kinetics productivity/unit time estimates, labor cost evaluations and for phase issues. The fuels we get are not drop-in gasoline or diesel replacements. Another factor is the specific cost of the olefin and alcohol components employed. Also, as long as their prices significantly exceed their values as fuels, substantial uses of these components would make this route uneconomical. However, if substantial amounts of low cost $\mathrm{C} 3$ to $\mathrm{C} 4$ alcohols (pure or mixtures) can be derived from biomass fermentation, these prices could decrease. However, for the present, the general concept has been demonstrated. This upgrading process can be used to produce oxygenated fuels, which can be blended with petroleum fuels or biodiesel liquids and might have promise for application in low temperature/high compression diesel engines requiring low cetane number fuels someday. This approach allows all of the bio-oil's caloric content to remain in the product because no carbon or hydrogen is removed and no hydrogen is consumed.

\section{Experimental Section}

\subsection{Materials}

All chemicals were purchased from Sigma Aldrich (St. Louis, MO, USA), and used without further purification unless otherwise noted.

\subsection{Catalyst Preparation and Characterization}

The silica sulfuric acid (SSA) was prepared by reacting silica gel with chlorosufonic acid in dichloromethane (Scheme 1) according to a well-developed procedure [28]. The obtained SSA catalyst was identified by its IR bands ( $\mathrm{Si}-\mathrm{O}-\mathrm{Si}$ bridge stretching at ca. 1000 to $1100 \mathrm{~cm}^{-1}$, Si-OH stretching at $971 \mathrm{~cm}^{-1}$, symmetrical and asymmetrical S-O stretching at 852 and $886 \mathrm{~cm}^{-1}$, asymmetric $\mathrm{S}=\mathrm{O}$ stretching at $1178 \mathrm{~cm}^{-1}$ and hydrogen bonded hydroxyl groups at 3200-3500 $\left.\mathrm{cm}^{-1}\right)[29,31]$. The SSA exhibited a high acidity $\left(2.9 \mathrm{meq} \cdot \mathrm{g}^{-1}\right)$, a large BET surface area of $\left(308 \mathrm{~m}^{2} \cdot \mathrm{g}^{-1}\right)$ and a high pore volume $\left(0.509 \mathrm{~cm}^{3} \cdot \mathrm{g}^{-1}\right)$, giving the SSA high catalytic performance in the experimental conditions. 
Negligible decreases of the once used SSA catalyst's acidity amount $\left(2.7 \mathrm{meq} \cdot \mathrm{g}^{-1}\right)$, surface area $\left(302 \mathrm{~m}^{2} \cdot \mathrm{g}^{-1}\right)$ and pore volume $\left(0.498 \mathrm{~cm}^{3} \cdot \mathrm{g}^{-1}\right)$ displayed its good reusability [31].

\subsection{Bio-Oil Production and Characterization}

Crude bio-oil was obtained by fast pyrolysis of pine chips at $450{ }^{\circ} \mathrm{C}$ in an auger-fed reactor, at Mississippi State University. The specific operating conditions have been reported [30]. The water content of samples was determined by Karl-Fisher titration (ASTM D1744) [38] using a Cole-Parmer model C-25800-10 titration apparatus (Cole-Parmer Instrument Co., Chicago, IL, USA). Bio-oil pH values were determined in water using a method similar to those used for wood or soil. First, bio-oil $(1.00 \mathrm{~g})$ was stirred with water $(50 \mathrm{~mL})$, then the $\mathrm{pH}$ of the water was recorded using a calibrated $\mathrm{pH}$ meter model pH 11 (Cole-Parmer Instrument Co., Chicago, IL, USA). The compositions of crude bio-oil liquid products obtained from each reaction were identified on a Shimadzu QP2010S gas chromatograph (Shimadzu Scientific Instruments, Tokyo, Japan) equipped with a mass selective detector (GC-MS) using helium as the carrier gas. A SHRXI-5MS $(30 \mathrm{~m} \times 0.25 \mathrm{~mm}$ i.d. $\times 0.25 \mu \mathrm{m}$ film) capillary column was used with a 50:1 split ratio. The GC oven was programmed from an initial temperature of $40{ }^{\circ} \mathrm{C}(5 \mathrm{~min})$ followed by a $5{ }^{\circ} \mathrm{C} / \mathrm{min}$ increase to a final temperature of $280{ }^{\circ} \mathrm{C}$, and held for $5 \mathrm{~min}$. After a solvent delay of $2 \mathrm{~min}$, full scan mass spectra were acquired from 35 to $500 \mathrm{~m} / \mathrm{z}$. The mass spectrometer was configured for electron impact ionization at $70 \mathrm{eV}$, with an interface temperature of $225^{\circ} \mathrm{C}$ and a source temperature of $230{ }^{\circ} \mathrm{C}$. An auto-sampler and the same method were used for all product analyses. MS identification of the products was based on molecular mass, fragmentation patterns and by matching the spectra with a digital library. FT-IR spectra of bio-oil were recorded on a Thermo Nicolet 6700 spectrophotometer (Thermo Nicolet, Waltham, MA, USA). ${ }^{1} \mathrm{H}$ NMR spectra were obtained in $\mathrm{CDCl}_{3}$ on a Bruker Avance $300 \mathrm{MHz}$ NMR Spectrometer (Bruker Co., Rheinstetten, Germany). The caloric value was measured as the higher heating value (HHV) using combustion calorimetry. Elemental analysis were determined by Hazen Research, Inc., Golden, CO. Elemental carbon, hydrogen, and nitrogen analyses of the bio-oil samples were performed by combustion in pure oxygen at $950{ }^{\circ} \mathrm{C}$ and analysis of the $\mathrm{CO}_{2}, \mathrm{H}_{2} \mathrm{O}, \mathrm{NO}_{\mathrm{x}}, \mathrm{N}_{2}$, and $\mathrm{SO}_{\mathrm{x}}$ produced. Oxygen was determined by difference. The pyrolysis liquid densities were determined using a pycnometer according to ASTM standard D 4052. Kinematic viscosities of both initial raw bio-oil and upgraded bio-oil were obtained at $40{ }^{\circ} \mathrm{C}$ using a BrookField viscometer (model LV-DVI+) (Brookfield Engineering Laboratories, Inc., Middleboro, MA, USA).

\subsection{Experimental Set-up and Procedure}

Crude bio-oil (1.5 g), 1-octene (98\%, 0.6 g), 1-butanol (0.75 g), internal standard (99.9\% 1-dodecane, $0.02 \mathrm{~g})$ and SSA $(0.15 \mathrm{~g})$ were charged in a glass pressure reaction vessel sealed with a metal fitting and Teflon gaskets. The end fitting had a needle value and the glass vessel was equipped with a magnetic stirrer. Reactions were maintained for $3 \mathrm{~h}$ at $120^{\circ} \mathrm{C}$ using an external oil bath. Then, the reaction products were cooled to room temperature and the catalyst was removed by filtration or centrifugation. The compositions of crude bio-oil liquid products obtained from each reaction were identified by GC-MS. The percent conversion of both 1-octene and 1-butanol charged into the 
upgrading reactions, which underwent conversion to other products, was determined by the change in peak area versus that of the IS, n-dodecane.

\section{Conclusions}

Silica sulfuric acid (SSA), easily prepared by reacting silica gel with neat chlorosulfonic acid, shows a higher catalytic activity and hydrothermal stability than resin-anchored sulfonic acids in bio-oil upgrading with olefins plus alcohols at $120^{\circ} \mathrm{C}$. Acid-catalyzed upgrading bio-oil with olefins plus alcohols involves complex reactions and equilibria proceeding simultaneously and competitively. A synergy exists between alcohols and olefins. Addition of $\mathrm{C} 4$ alcohols reduces phase separations between hydrophobic olefins and hydrophilic bio-oil, increasing mass transport rates. This bio-oil upgrading system effectively inhibits oligomerization and condensation reactions and the formation of tar or coke. A sharp reduction or total elimination of tar or coke formation was previously noted when 1-butanol was added to bio-oil/olefin reactions over styrene/divinylbenzene resin sulfonic acid catalysts [24]. Bio-oil's fuel qualities were improved after upgrading treatment.

\section{Acknowledgments}

This material is based upon work performed at the MOE Key Laboratory of Bio-based Material Science and Technology at Northeast Forestry University and at the Department of Chemistry, Mississippi State University. This work was supported by the Fundamental Research Funds for the Central Universities under the Project Number DL13DBX04, by the National Key Technologies R\&D Program of China under the Project Number 2012BAD32B04 and by Department of Chemistry at Mississippi State University.

\section{Conflicts of Interest}

The authors declare no conflict of interest. 


\section{Appendix}

Table A1. Selected organic oxygen-containing components of raw bio-oil ${ }^{\mathrm{a}}$.

\begin{tabular}{|c|c|c|c|}
\hline Components & Area \% & Components & Area \% \\
\hline \multicolumn{2}{|l|}{ Acids } & \multicolumn{2}{|l|}{ Alcohols } \\
\hline Glyoxylic acid & 0.19 & Glycerin & 11.17 \\
\hline Formic acid & 1.16 & 1,2,3,4-Butanetetrol & 0.59 \\
\hline Acetic acid & 8.84 & 2,3-Dimethylcyclohexanol & 0.18 \\
\hline Propanoic acid & 1.70 & 3-Methoxy-1,2,4-butanetriol & 0.03 \\
\hline Butanedioic acid & 0.41 & \multicolumn{2}{|l|}{ Esters and acetals } \\
\hline 2-Hydroxy-3-methoxy-succinic acid & 0.17 & 2,2-Dimethoxypropane & 0.1 \\
\hline D-Araboascorbic acid & 0.20 & Hexanedioic acid, monomethyl ester & 0.58 \\
\hline Phenols & & Acetic acid, 2-propyltetrahydropyran-3-yl ester & 1.49 \\
\hline Phenol & 0.59 & \multicolumn{2}{|l|}{ Furans } \\
\hline 2-Methyl phenol & 0.22 & 2,5-Dimethylfuran & 0.92 \\
\hline 3-Methyl phenol & 0.37 & (2-Hydroxy-1-methoxy) ethylfuran & 0.18 \\
\hline 2-Methoxyphenol & 2.33 & 2(5H)-Furanone & 0.41 \\
\hline 2,6-Dimethylphenol & 0.26 & 2,3-Dihydro-2,5-dimethylfuran & 0.08 \\
\hline 2-Methoxy-4-methyl phenol & 3.44 & 2,5-Dimethoxytetrahydrofuran & 0.05 \\
\hline 1, 2-Benzenediol (catechol) & 0.98 & \multicolumn{2}{|l|}{ Sugars } \\
\hline 4-Ethyl-2-methoxy phenol & 0.75 & D-Arabinitol & 0.17 \\
\hline 2-Methoxy-5-propenyl phenol & 0.73 & 1-Deoxy-D-arabitol & 0.33 \\
\hline 2-Methoxy-4-propyl phenol & 0.15 & 2-Deoxy-D-galactose & 0.54 \\
\hline 1-(4-Hydroxy-3-methoxyphenyl)-2-propanone & 0.56 & 2,2-Dimethyl-3-heptanone & 0.60 \\
\hline 4-(3-Hydroxy-1-propenyl)-2-methoxy-phenol & 0.17 & 3-Deoxyglucose & 0.13 \\
\hline 5-Hydroxy-6-methoxy-1-benzofuran 3(2H)-one & 0.09 & 1,4:3,6-Dianhydro- $\alpha$-D-glucopyranose & 0.43 \\
\hline Ketones and aldehydes ${ }^{b}$ & & 2,3-Anhydro-D-galactosan & 0.69 \\
\hline 3-Hydroxy-2-butanone & 0.08 & 2,3-Anhydro-D-mannosan & 0.33 \\
\hline 1-Hydroxy-2-butanone & 0.46 & 3,4-Anhydro-D-galactosan & 1.93 \\
\hline 4-Hydroxy-3-methyl-2-butanone & 0.64 & D-Allose & 1.46 \\
\hline 2-Methyl-cyclopentanone & 0.14 & 1,6-Anhydro- $\beta$-D-glucopyranose(levoglucosan) & 44.13 \\
\hline 3-Methyl-1,2-cyclopentanedione & 1.45 & D-Glycero- D-galacto-heptose & 0.35 \\
\hline 2,2-Dimethyl-3-heptanone & 0.60 & D-Glycero- D-ido-heptose & 0.23 \\
\hline 4-Ethoxy-cyclohexanone & 0.17 & Diacetonyl-D-mannosan & 0.26 \\
\hline 4-Hydroxy-3-methoxy-benzaldehyde & 0.33 & \multicolumn{2}{|l|}{ Others } \\
\hline 4-Hydroxy-2-methoxycinnamaldehyde & 0.20 & 2,3-Dihydroxy-1,4-dioxane & 2.01 \\
\hline 2,3-Methylenedioxyanisole & 0.26 & 2-(2-Propenyl)-1,3-dioxolane & 0.38 \\
\hline Hexanedial & 0.33 & Octahydro-4a(2H)-naphthalenecarboxylic acid & 2.28 \\
\hline
\end{tabular}

Notes: ${ }^{a}$ The bio-oil was produced by fast pyrolysis in an auger-fed reactor at $450{ }^{\circ} \mathrm{C}$ from southern pine sawdust using the methanol described in reference $21 ;{ }^{\mathrm{b}}$ No hydroxylacetaldehyde (HAD) peak was detected, but 2,3-dihydroxy-1,4-dioxane, which is the cyclic dimmer of HAD, was detected. This appears to be due to the GC-column and conditions employed. 
Table A2. Selected organic oxygen-containing components of bio-oil upgraded with 1-octene/1-butanol at $120^{\circ} \mathrm{C}$ for $3 \mathrm{~h}^{\mathrm{a}}$.

\begin{tabular}{|c|c|c|c|}
\hline Components & Area \% & Components & Area \% \\
\hline \multicolumn{2}{|l|}{ Acids } & \multicolumn{2}{|l|}{ Esters } \\
\hline Glyoxylic acid & 0.15 & $n$-Butyl formate & 3.63 \\
\hline Acetic acid & 0.65 & $n$-Butyl acetate & 9.87 \\
\hline Propanoic acid & 0.05 & 2-Hydroxyethyl propionate & 0.07 \\
\hline 2-Octenoic acid & 0.08 & $n$-Butyl propanoate & 1.53 \\
\hline 2-Pentenoic acid & 0.09 & Butoxyhydroxyacetic acid, butylester & 0.89 \\
\hline Phenols & & $n$-Butyl butanoate & 0.46 \\
\hline Phenol & 0.10 & 2-Hydroxypropanoic acid, butyl ester & 0.40 \\
\hline 2-Methylphenol & 0.09 & 2-Butenoic acid, butyl ester & 0.26 \\
\hline 1-(4-Hydroxy-3-methoxyphenyl)-2-propanone & 0.15 & 2-n-Butoxyethanol & 0.03 \\
\hline 2-Methoxyphenol & 0.49 & Pentanoic acid, butyl ester & 0.03 \\
\hline 2,6-Dimethylphenol & 0.09 & Hexanoic acid, butyl ester & 0.06 \\
\hline 1-(4-Hydroxy-3-methoxyphenyl)-ethanone & 0.36 & 3-Hydroxybutanoic acid, butyl ester & 0.08 \\
\hline 2-Methoxy-4-methyl phenol & 0.57 & Levulinic acid, butyl ester & 2.06 \\
\hline 2-Methoxy-4-(2-propenyl)-phenol & 0.57 & Butanoic acid, octyl ester & 1.71 \\
\hline 2-Methoxy-4-propyl-phenol & 0.07 & Pentanoic acid, octyl ester & 0.73 \\
\hline 4-(Ethoxymethyl)-2-methoxyphenol & 0.25 & 2,3-Dihydroxypropyl propionate & 0.11 \\
\hline Octyl derivatives of phenols & 1.68 & 2,2-Dibutoxypropionic acid, butyl ester & 0.10 \\
\hline Ketones and aldehydes & & Hexanoic acid, octyl ester & 0.20 \\
\hline 1,2-Dimethoxycyclopentane & 0.09 & Butanedioic acid, dibutyl ester & 0.82 \\
\hline 2-Hydroxy-3-methyl-2-cyclopenten-1-one & 0.38 & Di(sec-butyl)-2-methylsuccinate & 0.42 \\
\hline 2-Methyl-2-cyclopentenone & 0.06 & Pentanedioic acid, dibutyl ester & 0.17 \\
\hline 1,2-Dimethoxy-cyclopentane & 0.09 & Octyl acetates & 1.26 \\
\hline 2-Allyl-2-methyl-1,3-cyclopentanedione & 0.16 & 4,4-Dibutoxybutyric acid, butyl ester & 0.72 \\
\hline $\begin{array}{ll}\text { Sugars } \\
\end{array}$ & & Hexanedioic acid, dibutyl ester & 0.10 \\
\hline Methyl- $\alpha$-D-glucopyranoside & 2.00 & Hexanedioic acid, diisooctyl ester & 0.11 \\
\hline 1,5-Anhydro-D-talitol & 0.11 & \multicolumn{2}{|l|}{ Furans } \\
\hline 1,5-Anhydro-D-mannitol & 0.12 & 5-Methyl-2(3H)-furanone & 0.03 \\
\hline Levoglucosan & 0.13 & 2-butoxytetrahydro-2H-pyran & 0.10 \\
\hline Ethyl- $\alpha$-D-glucopyranoside & 1.25 & \multicolumn{2}{|l|}{ Alcohols } \\
\hline Methyl- $\beta$-D-glucopyranoside & 0.98 & 1-Butanol & 13.22 \\
\hline 2-Deoxy-D-erythropentose & 0.08 & 2-Octanol & 0.05 \\
\hline 2,5-Monoformal-1-rhamnitol & 0.21 & 3-Octanol & 0.20 \\
\hline \multicolumn{2}{|l|}{ Acetals } & 2,2-Dimethyl-3-hexanol & 0.08 \\
\hline 2,2-Dimethoxypropane & 0.63 & \multicolumn{2}{|l|}{$\begin{array}{ll}\text { Others }\end{array}$} \\
\hline Formaldehyde dibutyl acetal & 0.23 & 1-Decene & 0.07 \\
\hline Acetaldehyde dibutyl acetal & 0.49 & 1-Dodecane & 10.28 \\
\hline 1,1-Dibutoxyacetone & 0.70 & 1-octene & 35.5 \\
\hline Di-tert-butoxymethane & 0.16 & 4-Octene & 0.38 \\
\hline 2,3-Dihydroxy-1,4-dioxane & 0.23 & 3-Octene & 0.19 \\
\hline 2-n-Butoxyethanol & 0.03 & 2-Octene & 0.07 \\
\hline 1,1-Dimethoxy-2-methylpropane & 0.11 & 3-Deoxy-D-mannonic acid & 0.22 \\
\hline 2,4,6-Dimethyl-1,3,5-trioxane & 0.04 & Glycerin & 0.09 \\
\hline
\end{tabular}

Note: ${ }^{a}$ The bio-oil/1-octene/1-butanol weight ratio (g) used was 1.5/0.6/0.75. 


\section{References}

1. Butt, D. Thermochemical Processing of Agroforestry Biomass for Furans, Phenols, Cellulose and Essential Oils; RIRDC Publication: Melbourne, Australia, 2006.

2. Amidon, T.E.; Wood, C.D.; Shupe, A.M.; Wang, Y.; Graves, M.; Liu, S.J. Biorefinery: Conversion of woody biomass to chemicals, energy and materials. J. Biobased Mater. Bioenergy 2008, 2, 100-120.

3. Huber, G.W.; Iborra, S.; Corma, A. Synthesis of transportation fuels from biomass: Chemistry, catalysts, and engineering. Chem. Rev. 2006, 106, 4044-4098.

4. Ragauskas, A.J.; Williams, C.K.; Davison, B.H.; Britovsek, G.; Cairney, J.; Eckeret, C.A.; Frederick, W.J., Jr.; Hallett, J.P.; Leak, D.J.; Liotta, C.L.; et al. The path forward for biofuels and biomaterials. Science 2006, 311, 484-489.

5. Mohan, D.; Pittman, C.U., Jr.; Steele, P.H. Pyrolysis of wood/biomass for bio-oil: A critical review. Energy Fuels 2006, 20, 848-889.

6. Diebold, J.P. A Review of the Chemical and Physical Mechanisms of the Storage Stability of Fast Pyrolysis Bio-Oils. In Fast Pyrolysis of Biomass: A Handbook; CPL Scientific Publishing: Newbury, UK, 2000; Volume 2, pp. 243-292.

7. Elliot, D.C.; Hart, T.R.; Neuenschwander, G.G.; Rotness, L.J.; Zacher, A.H. Catalytic hydroprocessing of biomass fast pyrolysis bio-oil to produce hydrocarbon products. Environ. Prog. Sustain. Energy 2009, 28, 441-449.

8. Vispute, T.P.; Zhang, H.; Sanna, A.; Xiao, R.; Huber, G.W. Renewable chemical commodity feedstocks from integrated catalytic processing of pyrolysis oils. Science 2010, 330, 1222-1227.

9. Venderbosch, R.H.; Prins, W. Fast pyrolysis technology development. Biofuels Bioprod. Biorefining 2010, 4, 178-208.

10. Mortensen, P.M.; Grunwaldt, J.-D.; Jensen, P.A.; Knudsen, K.G.; Jensen, A.D. A review of catalytic upgrading of bio-oil to engine fuels. Appl. Catal. A Gen. 2011, 407, 1-19.

11. Bulushev, D.A.; Ross, J.R.H. Catalysis for conversion of biomass to fuels via pyrolysis and gasification: A review. Catal. Today 2011, 171, 1-13.

12. Bridgwater, A.V. Review of fast pyrolysis of biomass and product upgrading. Biomass Bioenergy 2012, 38, 68-94.

13. Hu, X.; Gunawan, R.; Mourant, D.; Wang, Y.; Lievens, C.; Chaiwat, W.; Wu, L.P.; Li, C.Z. Esterification of bio-oil from mallee (Eucalyptus loxophleba ssp. gratiae) leaves with a solid acid catalyst: Conversion of the cyclic ether and terpenoids into hydrocarbons. Bioresour. Technol. 2012, 123, 249-255.

14. Sanna, A.; Andrésen, J.M. Bio-oil deoxygenation by catalytic pyrolysis: New catalysts for the conversion of biomass into densified and deoxygenated bio-oil. ChemSusChem 2012, 5, 1944-1957.

15. Wang, Z.; Lu, Q.; Zhang, Y.; Zhu, X.F. Catalytic fast pyrolysis of cellulose to prepare levoglucosenone using sulfated zirconia. ChemSusChem 2011, 4, 79-84.

16. Wan, Y.Q.; Chen, P.; Zhang, B.; Yang, C.; Liu, Y.; Lin, X.; Ruan, R. Microwave-assisted pyrolysis of biomass: Catalysts to improve product selectivity. J. Anal. Appl. Pyrolysis 2009, 86, $161-167$. 
17. Wang, Y.; He, T.; Liu, K.; Wu, J.; Fang, Y. From biomass to advanced bio-fuel by catalytic pyrolysis/hydro-processing: hydrodeoxygenation of bio-oil derived from biomass catalytic pyrolysis. Bioresour. Technol. 2012, 108, 280-284.

18. Zabeti, M.; Nguyen, T.S.; Lefferts, L.; Heeres, H.J.; Seshan, K. In situ catalytic pyrolysis of lignocellulose using alkali-modified amorphous silica alumina. Bioresour. Technol. 2012, 118, 374-381.

19. Thangalazhy-Gopakumar, S.; Adhikari, S.; Chattanathan, S.A.; Gupta, R.B. Catalytic pyrolysis of green algae for hydrocarbon production using H+ZSM-5 catalyst. Bioresour. Technol. 2012, 118, $150-157$.

20. Dickerson, T.; Soria, J. Catalytic fast pyrolysis: A review. Energies 2013, 6, 514-538.

21. Lu, Q.; Zhang, Z.F.; Dong, C.Q.; Zhu, X.F. Catalytic upgrading of biomass fast pyrolysis vapors with nano metal oxides: An analytical Py-GC/MS study. Energies 2010, 3, 1805-1820.

22. Yang, X.L.; Chatterjee, S.; Zhang, Z.J.; Zhu, X.F.; Pittman, C.U., Jr. Reactions of phenol, water, acetic acid, methanol, and 2-hydroxymethylfuran with olefins as models for bio-oil upgrading. Ind. Eng. Chem. Res. 2010, 49, 2003-2013.

23. Zhang, Z.J.; Wang, Q.W.; Yang, X.L.; Chatterjee, S.; Pittman, C.U., Jr. Sulfonic acid resin-catalyzed addition of phenols, carboxylic acids, and water to olefins: Model reactions for catalytic upgrading of bio-oil. Bioresour. Technol. 2010, 101, 3685-3695.

24. Zhang, Z.J.; Wang, Q.W.; Tripathi, P.; Pittman, C.U., Jr. Catalytic upgrading of bio-oil using 1-octene and 1-butanol over sulfonic acid resin catalysts. Green Chem. 2011, 13, 940-949.

25. Cheng, C.L.; Chien, L.J.; Lee, W.J.; Che, P.Y.; Chen, B.Y.; Chang, J.S. High yield bio-butanol production by solvent-producing bacterial microflora. Bioresour. Technol. 2012, 113, 58-64.

26. Okuhara, T. Water-tolerant solid acid catalysts. Chem. Rev. 2002, 102, 3641-3666.

27. Harmer, M.A.; Sun, Q. Solid acid catalysis using ion-exchange resins. Appl. Catal. A 2001, 221, $45-62$.

28. Minakata, S.; Komatsu, M. Organic reactions on silica in water. Chem. Rev. 2009, 109, 711-724.

29. Zhang, Z.J.; Sui, S.J.; Tan, S.; Wang, Q.W.; Pittman, C.U., Jr. Catalytic conversion of bio-oil to oxygen-containing fuels by simultaneous reactions with 1-butanol and 1-octene over solid acids: Model compound studies and reaction pathways. Bioresour. Technol. 2012, 130, 789-792.

30. Ingram, L.; Mohan, D.; Bricka, M.; Steele, P.; Strobel, D.; Crocker, D.; Mitchell, B.; Mohammad, J.; Cantrell, K.; Pittman, C.U., Jr. Pyrolysis of wood and bark in an auger reactor: Physical properties and chemical analysis of the produced bio-oils. Energy Fuels 2008, 22, 614-625.

31. Zhang, Z.J.; Pittman, C.U., Jr.; Sui, S.J.; Sun, J.P.; Wang, Q.W. Catalytic upgrading of bio-oil by reacting with olefins and alcohols over solid acids: Reaction paths via model compound studies. Energies 2013, 6, 1568-1589.

32. Boucher, M.E.; Chaala, A.; Pakdel, H.; Roy, C. Bio-oils obtained by vacuum pyrolysis of softwood bark as a liquid fuel for gas turbines. Part II: Stability and ageing of bio-oil and its blends with methanol and a pyrolytic aqueous phase. Biomass Bioenergy 2000, 19, 351-361.

33. Weingarten, R.; Cho, J.; Xing, R.; Conner, W.C., Jr.; Huber, G.W. Kinetics and reaction engineering of levulinic acid production from aqueous glucose solutions. ChemSusChem 2012, 5, $1280-1290$. 
34. Jiang, X.X.; Naoko, E.; Zhong, Z.P. Fuel properties of bio-oil/bio-diesel mixture characterized by TG, FTIR and ${ }^{1}$ H NMR. Korean J. Chem. Eng. 2011, 28, 133-137.

35. Pokorna, E.; Postelmans, N.; Jenicek, P.; Schreurs, S.; Carleer, R.; Yperman, J. Study of bio-oils and solids from flash pyrolysis of sewage sludges. Fuel 2009, 88, 1344-1350.

36. Pittman, C.U., Jr.; Mohan, D.; Eseyin, A.; Li, Q.; Ingram, L.; Hassan, E.M.; Mitchell, B.; Guo, H.; Steele, P.H. Characterization of bio-oils produced from fast pyrolysis of corn stalks in an auger reactor. Energy Fuels 2012, 26, 3816-3825.

37. Garcìa-Pérez, M.; Chaala, A.; Pakdel, H.; Kretschmer, D.; Rodrigue, D.; Roy, C. Multiphase structure of bio-oils. Energy Fuels 2006, 20, 364-375.

38. Standard Test Method for Determination of Water in Liquid Petroleum Products by Karl Fischer Reagent (Withdraw 2000); Withdrawn Standard: ASTM D 1744-92; American Society for Testing and Materials Publications: West Conshohocken, PA, USA, 1992.

(C) 2013 by the authors; licensee MDPI, Basel, Switzerland. This article is an open access article distributed under the terms and conditions of the Creative Commons Attribution license (http://creativecommons.org/licenses/by/3.0/). 